\title{
Developing Business Process Management Capabilities of Undergraduate IT Students
}

\author{
Muhammad Anwar-ur-Rehman Pasha, PhD. \\ Professor of IT \& Chairman \\ Department of Computer Science \& Information Technology \\ University of Sargodha
}

\begin{abstract}
In recent years, Business Process Management (BPM) has emerged as an effective management strategy and an efficient technological solution for managing cross-functional business processes. Software industry is striving to integrate more and more functionalities in their BPM products. For this, the industry needs professionals who are equipped with BPM capabilities. However, lack of appropriate BPM skilled professionals in the field is a commonly reported problem. Keeping in view the importance of BPM knowledge \& skills, a course of BPM is offered to IT undergraduate students to promote their process management capabilities. This longitudinal study, spread over fours semesters, has found that BPM knowledge and skills have strong connections with the IT curriculum and offering of BPM course to undergraduate students can strengthen their BPM capabilities. However, keeping in view the rapidly evolving nature of BPM field and associated technologies, the study identifies the need of standardized curriculum guidelines, to be developed in collaboration with academia and industry, to help the academic institutions to prepare students according to the needs of the employment market. It is believed the recommendations and the lessons learnt in this study may be useful for those who are seeking to strengthen their students' business process capabilities.
\end{abstract}

\section{General Terms}

Business Process Management, Business Process Management Education,

\section{Keywords}

Teaching of Business Process Management, Inherited relationship between BPM and IT, Scope of BPM, BPM education, BPM Scope

\section{INTRODUCTION}

The challenges of the $21^{\text {st }}$ century have compelled organizations to adopt a high level of agility, control and transparency [1]. Organizations now increasingly focus on a process view of management and concentrate on crossfunctional processes management approach rather than managing loosely connected functional components $[2,3,4$, 5]. In recent years, Business Process Management (BPM) has emerged as an effective management strategy as well as an efficient technological solution for managing cross-functional business processes. A rapidly growing number of enterprises and organizations are adopting BPMS to improve the performance of their business processes including those of human resource management, customer relationship management, supply chain management, Risk Management, Quality Control, Sales, Invoicing, etc. TechNavio's recent report 'Global Business Process Management Software Market 2011-2015' predicts that "the Global Business Process
Management Software market to grow at a CAGR of 12.9 percent over the period 2011-2015". The information technology community has also recognized the importance of BPM $[6,7,8,9,10]$.

Currently, many BPM technologies are available in the market offering a variety of functionalities, processes, analytics, and collaboration tools enabling organizations to build process oriented applications quickly and efficiently. Software industry is striving to integrate more and more functionalities in their BPM products. For this, the industry needs professionals who are equipped with an appropriate BPM skill set. However, lack of appropriate BPM skilled professionals in the field is a commonly reported problem [11, 12, 13]. Realizing this need, recently, many international universities have incorporated BPM coursework in their degree programs $[14,15,16]$.

Keeping in view the importance of BPM knowledge \& skills, at the University of Education, Lahore (Pakistan) a course of BPM has been integrated as a part of the undergraduate Information Technology (IT) program to promote students' process management capabilities. Through offering this course we aim to investigate whether it makes sense to incorporate a BPM course into an undergraduate IT program and how it ties with existing IT curriculum formulated by the Higher Education Commission of Pakistan. It is important to mention that by the time of this study, the course of BPM has not been offered to undergraduate IT students in any other Pakistani university.

The structure of the paper is as follow. The research methodology is discussed in Section 2. BPM scope and its relevance with IT are discussed in Section 3. The structure of the course and its delivery is covered in section 4. Data analysis and the experiences and lessons learnt from this exercise are presented in the next two sections. It is believed, the recommendations made in this paper may be useful for those who are seeking to strengthen their students' business process capabilities.

\section{METHODOLOGY}

In contrast to cross-sectional studies which are carried out at a single point in time, longitudinal studies are used to find answers to questions which may change from time to time [17]. This study is a longitudinal exploratory research which is carried out to explore some well-defined research questions.

In this longitudinal study, spread over 2 years (Fall \& Spring 2009 and Fall \& Spring 2010), two different methods are utilized in order to have a wider understanding of the research problem: 
1. Desktop research: in this part widely reviewed and cited articles published in research journals and conference proceedings, case studies, white papers, technical reports, and material available on the Internet is used to review existing literature on the concept of BPM and associated technologies.

2. Survey: In this part a survey has been designed to test the following research questions:

- Do BPM concepts and practices have inherent connections with the IT curriculum?

- Does it make sense to offer BPM course in an undergraduate IT program?

- What are the options to integrate BPM body of knowledge in an undergraduate IT curriculum?

A questionnaire is used in this survey to collect primary data from students studying in the undergraduate IT program.

Through this questionnaire, at the end of each semester qualitative feedback and quantitative evaluation were sought from each student. To ensure the participants' confidentiality and anonymity the students were asked not to mark their names or roll numbers on the questionnaire.

The quantitative evaluation was sought from each student regarding the organization and structure of course, delivery of the contents, knowledge \& skills relevancy, students' learning outcomes, and their course satisfaction. Whereas, the quantitative evaluation is based on following six key statements:

S1. The course contents are well organized and structured.

S2. I am satisfied with the delivery of the course contents.

S3. The course has provided valuable knowledge and skills.

S4. BPM knowledge and skills are relevant for my career.

S5. BPM course is very useful for BSIT program

S6. I am satisfied with the learning outcome of the course.

The quantitative evaluation was measured on a 5-point Likert scale $($ Very Dissatisfied $=1$, Dissatisfied $=2, \quad$ Neutral $=3$, Satisfied = 4, and Very Satisfied =5).

\section{BPM SCOPE \& RELEVANCE}

BPM is an emerging field of study which has grown steadily over recent years. It is creating a noticeable impact on today's technology driven business world. In literature, many definitions of BMP are presented. The Association of Business Process Management Professionals defines BPM as: “... a disciplined approach to identify, design, execute, document, monitor, control, and measure both automated and non-automated business processes to achieve consistent, targeted results consistent with an organization's strategic goals." Ashton and Kelly (2006)[18] comment that BPM solutions allow organizations to maximize the productivity of their existing technology infrastructure and human resource by linking existing systems and automating business processes that can free humans to add value elsewhere within the organization.

As a discipline, BPM has evolved from two parallel strands: management and technology. From management strand BPM follows 1980's management guru Geary Rummler who advocates for a customer-centric end-to-end process approach and suggests managing those areas that get in the way of efficiency and customer satisfaction. From technology strand, BPM follows the workflow wave of the nineties which provides business process modeling and process control methodologies to improve efficiency [19]. However, BPM goes one step ahead and integrates various existing technologies. In his article Vickesh Dhookie [20] comments that "BPM unifies the previously distinct disciplines of Process Modeling, Simulation, Workflow, Enterprise Application Integration and Business to business integration into a single organizational platform or infrastructure".

In the world of today's hyper-competition and continuous change, BPM advocates for a cross-functional process approach which helps organizations to become more agile and efficient. It is important to mention that in the early 1990s, Business Process Reengineering (BPR) emerged a new wave to enhance organizational efficiency and/or add value. Although BPR had enormous promises, its implementation fails to produce the desired results [21]. Whereas, BPM software solutions can enable organizations to improve their performance, increase revenue and assure customer satisfaction [22]. In parallel, organization demands workers who have the capabilities to identify and document organizational business processes for process analysis, performance measurement, improvement, or redesign [23]. Such aspects make BPM capabilities the number one skill demanded in the IT employment market [24].

As an academic discipline BPM is gaining popularity among the academic community. It is offered in many universities across the globe. Delavari [16] gives an overview and comparison of BPM courses offered in Australian institutions. Bandara et al. [25] discuss the scope of BPM education in academia. Targowski et al. [26] have edited a book describing various approaches of enterprise systems education. Jæger, et al. share their experiences of teaching Business Process Concepts [27]. Recker, et al. [28] have shared their experiences of teaching business process modeling course to university students.

\section{COURSE STRUCTURE \& DELIVERY}

This course of Business Process Management is taught as an elective course to the students studying in $6^{\text {th }}$ semester of an undergraduate IT program at the University of Education, Lahore, Pakistan.

For structuring this course, a literature review was conducted to learn about the core BPM capabilities. In this regard, Rosemann et al. [29] BPM Maturity model and Harmon's business process pyramid [30] were explored in detail. Harmon's business process pyramid takes a holistic view and establishes a link between strategy and IT to justify the business value for BPM initiatives. It is a globally accepted model describes different business process activities that occur at different levels within an organization. Whereas, Rosemann et al. BPM Maturity model covers a broader scope and describes BPM capabilities and achievements within an organization. It is based on an established theoretical foundation and is a globally accepted standard. In addition, the BPM Common Body of Knowledge (CBOK) proposed by ABPMP [31] is used as a basis for this course. The CBOK identifies nine knowledge areas: business process management, process modeling, process analysis, process design, process performance management, process 
transformation, process organization, enterprise process management, and BPM technology.

As the course is offered to IT students, the course contents focus more on IT aspects of BPM and are selected to address the needs of technologist who tend to have a focus on the technical aspects of BPM to address the managerial issues related to the process-centered design of organizations. The selected contents also intend to teach students how to integrate people, technology and processes to produce an agile organization. Therefore we have also included some other knowledge areas like Knowledge Management, Enterprise Architecture, Service Oriented Architecture, Business Process Modeling Language, Extensible Process Definition Language, Business Process Execution Language and BPM career path.

For achieving course objectives we have adopted a problembased experiential learning and a team-based approach for the teaching of this course. The students were provided with opportunities to work on real-world projects. Incorporation of real-world projects enhances students' understanding regarding the practical aspects of the taught concepts.

During the course execution the students were encouraged to integrate BPM concepts and skills in other courses as well. In addition, following strategies were adopted for selecting course contents, teaching -learning activities and evaluation methodology:

- "Selective Abandonment" strategy [32] was adopted for the selection of course contents. It allows instructors to prioritize the content of instructional material into three categories: i) essential material which must be covered and have top priority, ii) supportive material which may be dealt with in conjunction with other material or as an independent learning experience, and iii) extraneous material which can be included as time allows.

- Biggs's constructive alignment [33] is adopted for selecting teaching-learning activities. Constructive alignment asks to move from behaviorist pedagogy to constructivist pedagogy through stating the curriculum objectives in terms of the level of understanding required of a student than just listing the topics to be covered [34].

- For measuring students' attainments both Formative \& Summative evaluation methods are used. Particularly, the formative assessment enables teachers to gather information about their students' learning and to use that information to improve the way that they learn [35].

\section{DATA ANALYSIS}

A summary of the results of the study, covering two years of data (Fall \& Spring 2009 and Fall \& Spring 2010) is presented in this section. At the end of each semester qualitative feedback and quantitative evaluation were sought from each student. The quantitative evaluation was sought from each student about the organization and structure of course, delivery of the contents, knowledge \& skills relevancy, students' learning outcomes, and their course satisfaction. The students' responses were measured on a 5-point Likert scale.

The number of students enrolled in this course is shown in Table 1. The students' feedback of Fall \& Spring 2009 and Fall \& Spring 2010 regarding six key statements are shown in Table 2 and Table 3 respectively. An average of Mean Score and Standard Deviation (St. Dev.) of Year 2009 and 2010 is shown in Table 4.

\begin{tabular}{|c|c|c|c|}
\hline \multicolumn{4}{|c|}{ Table 1 } \\
\hline \multicolumn{4}{|c|}{ Number of Students Enrolled in the Course } \\
\hline Fall 2009 & Spring 2009 & Fall 2010 & Spring 2010 \\
\hline 37 & 42 & 45 & 45 \\
\hline
\end{tabular}

\begin{tabular}{|c|c|c|}
\hline \multicolumn{3}{|c|}{ Table 2 } \\
\hline \multicolumn{3}{|c|}{ Fall \& Spring 2009 } \\
\hline S. No. & Mean Score & St. Dev \\
\hline S1 & 4.03 & 0.86 \\
\hline S2 & 4.03 & 0.48 \\
\hline S3 & 4.38 & 0.49 \\
\hline S4 & 4.38 & 0.49 \\
\hline S5 & 4.38 & 0.49 \\
\hline S6 & 4.15 & 0.80 \\
\hline
\end{tabular}

\begin{tabular}{|c|c|c|}
\hline \multicolumn{3}{|c|}{ Table 3 } \\
\hline \multicolumn{3}{|c|}{ Fall \& Spring 2010 } \\
\hline S. No. & Mean Score & St. Dev \\
\hline S1 & 3.93 & 0.97 \\
\hline S2 & 3.98 & 0.53 \\
\hline S3 & 4.50 & 0.51 \\
\hline S4 & 4.50 & 0.51 \\
\hline S5 & 4.33 & 0.47 \\
\hline S6 & 4.28 & 0.88 \\
\hline
\end{tabular}

\begin{tabular}{|c|c|c|}
\hline \multicolumn{3}{|c|}{ Table 4 } \\
\hline \multicolumn{3}{|c|}{ Cumulative 2009-2010 } \\
\hline S. No. & Mean Score & St. Dev \\
\hline S1 & 3.98 & 0.92 \\
\hline S2 & 4.00 & 0.51 \\
\hline S3 & 4.44 & 0.50 \\
\hline S4 & 4.44 & 0.50 \\
\hline S5 & 4.35 & 0.48 \\
\hline S6 & 4.21 & 0.84 \\
\hline
\end{tabular}

The analysis revealed that the students were mostly satisfied with the delivery of course contents (mean score 4.0, standard deviation 0.51). Specifically, students perceived the course as highly relevant for their career (mean score 4.44, standard deviation 0.50$)$ as it equipped them very valuable knowledge and skills (mean score 4.44, standard deviation 0.50). They also consider the BPM course very useful for undergraduate IT students (mean score 4.35, standard deviation 0.48). However, they were less satisfied with the structure of the course and considered the course contents could be organized in a more effective way (mean score 3.98, standard deviation $0.92)$.

In their descriptive feedback many students considered the course contents overcrowded and were challenging for them. In general the students appreciated course contents, practical assignments and delivery of the contents. However, nonavailability of a textbook was challenging to the majority of the students. It is important to mention that except this course all other courses of the undergraduate program follow textbooks. However, for some students this was an interesting experience which helped them to learn about the research and discovery aspects of higher education. As one student comments "Finding relevant material on the Internet was very time consuming, but I learnt about many useful things which could never be possible just following a textbook." 
Another student comments, "I liked the contents and assignment which were very helpful for my Web Engineering course. I am very confident it will also help me to study my ERP course in the next semester". These comments realize the challenging but usefulness of BPM course for undergraduate IT students.

\section{CONCLUSION AND RECOMMENDATIONS}

For developing an effective IT solution, IT graduates need to have knowledge about three broad areas: Information Management, Process Management, and ERP Systems. Some of the relevant courses are already included in the existing IT curriculum like Computer Programming, Database Design \& Management, Systems Analysis and Design, Software Engineering, Web Engineering. They also study courses like Principles of Accounting, Principles of Management, Human Resource Management, and Project Management. However, the existing curriculum fails to develop students' knowledge and skills in areas like process modeling, design, improvement, and inter-organizational standards and processes, etc.

As discussed above BPM has emerged as an effective management strategy and an efficient technological solution for managing cross-functional business processes. In Global Business Process Management Report [22], Bob Scott Senior Vice President of Global Head of BPM, Capgemini comments, "Business Process Management is becoming ever more relevant to both large and small organizations in the current economic climate. At a time when many different market sectors are facing slow revenue growth, customer churn and increased pressures on costs, BPM becomes a critical weapon in the battle for efficiency and effectiveness in processes." These aspects make BPM capabilities as number one skill in the employment market. Organizations including software industry need professionals who are equipped with appropriate BPM capabilities. It has become imperative for academic institutions to strengthen their students' process management capabilities to increase the chances of their graduates' employability.

Our experience of integrating a BPM course in the undergraduate IT curriculum at the University of Education was both academically challenging and exciting. For the designing of this course, in addition to seeking guidelines from Rosemann et al. [29] BPM Maturity model and Harmon's business process pyramid [30], we follow the CBOK recommended by ABPMP which includes nine key knowledge areas. As the course is offered to IT students, so we have also included some other knowledge areas like Knowledge Management, Enterprise Architecture, Service Oriented Architecture (SOP), an Overview of Extensible Process Definition Language (XPDL), Business Process, Modeling Language (BPML), Business Process Execution Language and BPM career path.

During the design and conduct of this course we learnt a number of lessons. Some of these which may be useful for those who are intended to introduce a BPM course(s) in IT curriculum are listed below:

- For developing students' process oriented thinking (disposition) teaching of one BPM course is not enough. It is believed that in addition to knowledge and skills, developing students' process oriented thinking (disposition) can help them to use methods and tools more effectively.

- Process oriented approach should be integrated in other courses as well especially courses like Information Systems, Software Engineering, Object Oriented System Analysis and Design, and Web Engineering.

- Due to over expected learning attainments and overcrowded course contents, the course failed to provide an effective learning environment in which students can strengthen their methodological and technical knowledge and skills. Although, the students learnt about various BPM concepts, tools and technologies, but they fail to apply the learnt knowledge to unseen problems. For example, in the final exam majority of the students failed to develop a process model of a complex scenario. It may be due to their lack of background knowledge. We believe BPM is a broad area. At least two courses should be included in the undergraduate IT curriculum. The first course should concentrate on the basic concepts, tools and technologies. The second course addresses the more practical and advanced concepts to strengthen students BPM practical skills.

- Non availability of a textbook was considered one of the major problems by many students. Although a large number of materials are available on the Internet, the students face difficulty in extracting relevant material from the Internet.

- As the topics of BPM and BP were new for the students, many students face difficulty in grasping the very basic concepts at the start of the course. The time spent on such concepts could be utilized in teaching of other core concepts if an introduction of these concepts is incorporated in courses which are offered in earlier semesters.

Related to the research questions we found that BPM concepts and practices have very strong connections with the IT curriculum. Therefore, offering a BPM course within the undergraduate IT curriculum is very helpful to strengthen students' BPM capabilities. Regarding the integration of BPM body of knowledge, in the light of our experiences and the latest literature, we suggest a course of BPM may be integrated in the undergraduate IT curriculum. However, for preparing students to meet the emerging challenges of the software industry, process oriented approach may also be integrated into other courses as well.

Finally, as the BPM field and associated technologies are evolving rapidly, it is suggested that, similar to computing curricula developed by the Association for Computing Machinery (ACM) and the Institute of Electrical and Electronics Engineers (IEEE), the Association of Business Process Management Professionals (ABPMP) also develop standard curriculum guidelines and attainment standards in collaboration with academia and industry for both management and technology programs. Such efforts will help the academic institutions to prepare students according to the needs of the employment market.

\section{FUTURE WORK AND RESEARCH LINES}

The author has now joined the Department of Computer Science \& Information Technology, University of Sragodha (Pakistan) where he will be offering the course of BPM to the 
students of three undergraduate degree programs: Information Technology, Computer Science and Software Engineering. This will extend the scope of research and provides an opportunity to investigate the research questions with respect to these three computing domains.

\section{REFERENCES}

[1] Amah, E. \& Baridam, D. 2012. Adaptability and Organizational Effectiveness: A Study Of the Nigerian Banking Industry, International Journal of Business and Management Tomorrow, 2 (3).

[2] Hammer, M. 1996. Beyond reengineering: How the process-centered organization is changing our work and our lives. New York: Harper Collins.

[3] Carpinetti L., Buosi, T., \& Gerolamo, M.C. 2003.Quality management and improvement: a framework and a business-process reference model, Business Process Management Journal, 9(4), 543-554.

[4] Trkman, P. 2010. The Critical Success Factors of Business Process Management, International Journal of Information Management, 30(2), 125-134.

[5] Botzenhardt, A., Meth, H. \& Maedche, A. 2011. CrossFunctional Integration of Product Management and Product Design in Application Software Development: Exploration of Success Factors, in Thirty Second International Conference on Information Systems, Shanghai.

[6] Curtis, B., Kellner, M.I., \& Over, J. 1992. Process Modeling. Communications of the ACM, 35(9),75-90.

[7] Dumas, M., Aalst, W. M. P. \& Hofstede, A. H. .2005. Process-Aware Information Systems: Bridging People and Software Through Process Technology, WileyInterscience.

[8] Skalle, H., Ramachandran, S., Schuster, M., Szaloky, V., \& Antoun, S. 2009. Aligning Business Process Management, Service-Oriented Architecture, and Lean Six Sigma for Real Business Results, IBM Corp.

[9] Beimborn, D. \& Joachim, N. 2011. The joint impact of service-oriented architectures and business process management on business process quality: an empirical evaluation and comparison, Journal Information Systems and e-Business Management archive, 9(3), 333-362.

[10] Tsai T-M, Huang W-S, Chang C-C, Wu F-T, Chou S-c. 2007. eXFlow: a web services-compliant system for supporting B2B process integration. Information Systems E-Business Management, 5(1),47-64.

[11] Bandara, W., Indulska, M., Chong, S. \& Sadiq, S. 2007. Major Issues in Business Process Management: An Expert Perspective, $15^{\text {th }}$ European Conference on Information Systems, St. Gallen, Switzerland: University of St. Gallen, 1240-1251.

[12] Zur Muehlen, M. .2008. Class Notes: BPM Research and Education - A Little Knowledge is a Dangerous Thing, BPTrends, 5(1), 1-5.

[13] Indulska, M., Recker, J., Rosemann, M. \& Green, P. 2009. Process Modeling: Current Issues and Future Challenges, in van Eck, P., J. Gordijn, and R. Wieringa (eds.) Advanced Information Systems Engineering CAiSE 2009 Amsterdam, The Netherlands: Springer, 501-514.
[14] Pal, R. \& Sen, S. 2011. Relevance of Business Process Management (Bpm) Course on Business School Curriculum \& Course Outline, AMCIS 2011 Proceedings

[15] Recker, J. C. \& Rosemann, M. (2009). Teaching business process modelling: experiences and recommendations. Communications of the Association for Information Systems, 25(32), 379-394.

[16] Delavari, H., Bandara, W., Marjanovic, O. \& Mathiesen, P. 2010. Business Process Management (BPM) education in Australia: a critical review based on content analysis. In Rosemann, M., Green, P., \& Rohde, F. (Eds.) ACIS2010 Proceedings, AIS Electronic Library, Queensland University of Technology, Brisbane, Qld.

[17] Lynn, P. (ed.) (2009). Methodology of Longitudinal Surveys. Hoboken, NJ: John Wiley and Sons.

[18] Ashton, H. \& Kelly, D. 2006. The Business Impact of BPM with SOA: Building a Business Case for BPM with SOA ROI, Upside Research, Inc., Newton, MA

[19] Georgakopoulos, D., Hornick, M. \& Sheth, A. (1995). An Overview of Workflow Management: From Process Modeling to Workflow Automation Infrastructure, Distributed and Parallel Databases, 3, 119-153.

[20] Dhookie, V. 2008.To Know the Future Know the Past, BPMInstitute.org http://www.ayokait.eu/images/pdf/1/BPMKnowthefuture knowthepast- Dhookie.pdf

[21] Goksoy, A., Ozsoy, B. \& Vayvay, O. 2012. Business Process Reengineering: Strategic Tool for Managing Organizational Change an Application in a Multinational Company, International Journal of Business and Management, 7(2),80-112.

[22] Capgemini (2012). Global Business Process Management Report, www.capgemini.com/globalbpmreport

[23] Recker, J., Rosemann, M., Indulska, M., \& Green, P. (2009). Business Process Modeling: A Comparative Analysis. Journal of the Association for Information Systems, 10(4), 333-363.

[24] Top 10 technology skills, Network World, Inc http://www.networkworld.com/news/2009/040609-10tech-skills.html

[25] Bandara, W., Chand, D. R., Chircu, A. M., Hintringer, S., Karagiannis, D., Recker, J. C., van Rensburg, A., Usoff, C. \& Welke, R. J. 2010. Business process management education in academia: Status, challenges, and recommendations, Communications of the Association for Information Systems, 27, 743-776.

[26] Targowski, A., S. \& Tarn, J., M. 2007. Enterprise Systems Education in the 21st Century, Information Science Publishing, Idea Group.

[27] Jæger, B., Rudra, A., Aitken, A., Chang, V. \& Helgheim, B. (2010).Teaching Business Process Concepts Using Enterprise Systems in a Globalized Context. HICSS-43: Hawaii International Conference on System Sciences, Kauai, Hawaii, Jan 4-8, 2010.

[28] [28] Recker, J. C. \& Rosemann, M. 2009. Teaching business process modelling: experiences and recommendations. Communications of the Association for Information Systems, 25(32), 379-394. 
[29] Rosemann, M, deBruin, T \& Power, B. 2006. A model to measure business process management maturity and improve performance in Jeston, J \& Nelis, J (eds.) Business Process management: practical guidelines to successful implementations, Butterworth-Heinemann, Oxford.

[30] Harmon, P. 2007. Business Process Change. A Guide for Business Managers and BPM and Six Sigma Professionals, (2nd ed.), Morgan Kaufman Publishers., Amsterdam

[31] ABPMP 2009, Guide to the Business Process Management Common Body of Knowledge (BPM COK), (2nd ed.), Association of Business Process Management Professionls.
[32] Lovely, S., \& Smith, S. (2004). Selective abandonment: How and when to say no. Principal Leadership, 5(3), 3538 .

[33] Biggs, J. 1996. Enhancing teaching through constructive alignment. Higher Education, 32, 1-18.

[34] Biggs, J. 2003. Teaching for quality learning at university, (2nd ed), The Society for Research into Higher Education, Buckingham: Open University Press.

[35] Clarke, S. 2005. Formative Assessment in Action: Weaving the Elements Together, Hodder Education. 